\title{
A JULGAR PELA IMAGEM: ESTADO AUTORITÁRIO E A CAÇA ÀS ALTERIDADES
}

\section{Ana Emília da Costa Silva}

Universidade do Estado do Rio de Janeiro

\section{RESUMO}

O Estado-Leviatã, teorizado por Hobbes como ordenador e violento, ainda é um conceito-chave para pensarmos as representações do corpo na contemporaneidade. A partir desse fio condutor, discute-se o papel da fotografia na manutenção dos estereótipos e na ficcionalização da violência. Questões sobre pertencimento, punição e estratégias de sobrevivência dos socialmente excluídos são assuntos pontuais. Obras de Rosana Paulino, coletivo Garapa, trechos do filme Ôrí (1989) e fotografias do início do século XX pelos fotógrafos Chichico e Assis Horta são alguns dos objetos de reflexão. A pesquisa apresenta uma cartografia das expressividades silenciadas pelas políticas de repressão em diálogo como os retratos criminalistas do século XIX, fotografias científicas e retratos para documentos oficiais, os quais apresentam padrões de enquadramento social úteis a políticas sanitaristas. Diana Taylor, Grada Kilomba e Jota Mombaça auxiliam a revisitar acervos imagéticos sobre o corpo fotografado, ampliando a discussão acerca da perseguição às alteridades.

Palavras-chave: Imagens fotográficas. Alteridade. Corpo. 


\section{Pertencimento ou punição}

O seu coração é duro como uma rocha, é como uma mó, de moinho. Quando se ergue, até os mais valentes têm medo, e ficam paralisados de terror. Não há espada que o detenha, nem qualquer outra arma, seja lança, dardo ou flecha. (Bíblia, Jó, 41, 24-26).

eviatã é uma criatura temida pelos navegantes e ilustrada em diferentes cultu$\checkmark$ ras, em especial na Bíblia hebraica e nas passagens de Jó. Trata-se de um misterioso monstro marinho que defendia os peixes mais fracos dos peixes mais fortes. Curiosamente, essa foi também a imagem de corpo político (HARDT; NEGRI, 2005, p. 209)' inspiradora do conceito de "Estado", teorizado pelo intelectual jurista Thomas Hobbes. As representações do Leviatã concebem o Estado hobbesiano a partir de uma espécie de senso de justiça, sendo sua função maior zelar pelo bem comum, não permitindo que uns atentem contra a vida dos outros. Para garantir a supremacia do Estado, na visão de Hobbes, era necessário um pacto de obediência entre os cidadãos e a indispensável violência disciplinadora dos órgãos de sua gestão. O monstro/Estado seria, por um lado, o representante do povo, imagem personificada do coletivo. Por outro lado, deveria ser cruel com toda e qualquer individualidade ameaçadora de seu poder. Ilustrado por Abraham Bosse, na capa do livro homônimo, o Leviatã ainda hoje dá arcabouço para o entendimento conceitual de corpo político.

1 Os autores falam sobre os primeiros tratados de política modernos, a destacar De corpore e sua alusão ao corpo coletivo como organismo vivo em que cada órgão cumpre a sua função natural básica. 


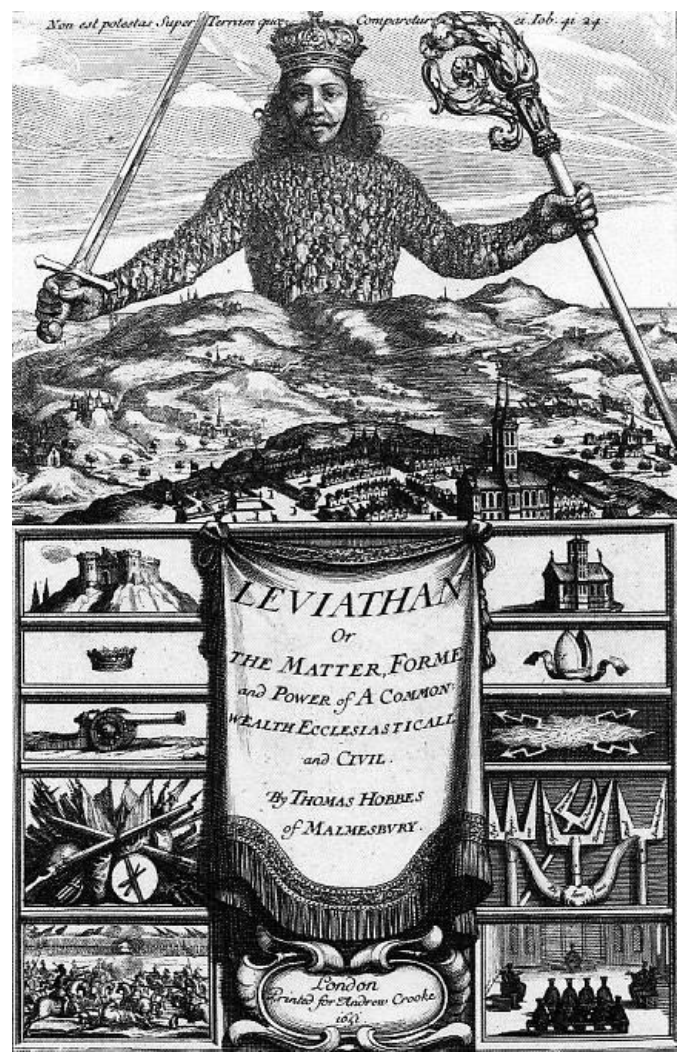

Figura 1 - Abraham Bosse, Leviatã, 1651, gravura (fonte: Wikimedia Commons)

Um nobre coroado, líder monarca, é ilustrado acumulando em seu domínio os poderes executivo, legislativo, judiciário e mercantilista. A espada em sua mão direita Ihe serve como mecanismo de defesa e ataque, representa ainda o poder civil. $O$ cetro marca, por sua vez, a parceria do Estado com a Igreja, uma aliança que centraliza a moral como potência cívica. Na parte inferior da gravura à qual fazemos menção, a cidade aparece ordenada por cenas em que os aparatos militar e religioso e a propriedade privada exprimem os valores do Leviatã. No topo da imagem está a inscrição "Non est potestas super terram quae comparetur ei", que quer dizer "Não há poder na Terra que se compare a ele". Inscrição esta retirada da Bíblia nas passagens de Jó. Centralizados estão o título e o subtítulo, índices sobre o conteúdo a ser abordado na obra de Hobbes. Na tradução para o português, temos: Leviatã, palavra e poder de um governo eclesiástico e civil. Se levado em consideração o período em que fora publicada a obra, fica clara a alusão à formação dos Estados europeus, estrutura que forneceria aparato para a economia liberal, identidade nacional e a dinâmica capitalista entre países (SMITH, 1984) do Ocidente.

Em seu livro, Hobbes afirma que, "se a felicidade pessoal é o fim, o poder é o meio de realizá-la num mundo naturalmente competitivo" (HOBBES, 1983, cap. XI, p. 60). Para o autor, a natureza do indivíduo é competitiva, portanto, sem o artifício do Estado, viveríamos uma barbárie e estaríamos fadados à guerra de todos contra 
todos, daí a necessária repressão. Essa força expressiva do Leviatã busca inspirar um consenso em relação aos valores racionais do que seria justo, verdadeiro e correto para o coletivo. Ao mesmo tempo, garante a adesão dos cidadãos às tomadas de decisão das grandes lideranças. O que, metaforicamente, seriam as cabeças pensantes desse corpo coletivo.

Fácil perceber, por que os ditames da razão para que tenham efeito, dependem de algo mais que torne seu acatamento obrigatório. Aliás, quem em pleno gozo de seu juízo, se disporia a agir de conformidade com eles sem ter a garantia de que os outros também o farão? Quem aceitaria para si o papel de cordeiro estando na iminência de seu atraiçoado por um lobo? (HOBBES, 1983, cap. XIV, p. 79-80).

Os cidadãos, anestesiados com a força e o medo imposto por Leviatã, são convencidos de que o contrato social é útil para fazer valer a vontade coletiva, pois representa a racionalidade em contraposição aos desejos individuais alimentados pelas paixões. Em um universo compreendido entre a escassez e a ameaça, o medo é justificável. Não por acaso, o contrato social, que garante a existência e o funcionamento do Estado, só ganha materialidade pela escrita, uma forma de poder além e acima das relações interpessoais, uma abstração fundamentada na linguagem e garantida pela lei. É nesse contexto que a imagem do Leviatã, segundo Hobbes, traduz o espelho da racionalidade do Estado, coletividade artificial firmada por uma imagem soberana e violenta. Entretanto, cabe aos representantes, reguladores e, portanto, senhores das ações do Leviatã, interpretarem e aplicarem as leis. Ao retornarmos à ilustração, a cabeça separada do corpo faz alusão à distinção entre representantes e representados. Ela é o ponto alto do desenho, o ápice da hierarquia de poderes e a única forma corporal desenhada em detalhes. Na parte superior do corpo coletivo, temos o exercício do poder político, enquanto, na representação dos membros e do tronco, aparece o povo, uma massa amorfa, base de sustentação do mecanismo regulatório.

Sob diferentes formas, essa relação entre representantes e representados (cabeça e corpo) é uma relação que persiste na constituição dos corpos coletivos eurocêntricos, que trazem a subjetivação da política como substituta da efetiva participação política. O que seria, na ilustração de Bosse, correspondente ao rosto do monarca, representante do povo, e seus representados, por sua vez, destituídos de rosto e de poder de decisão.

Segundo Rancière (2010), o sensível coletivo é o lugar onde se formam os territórios de dominação e igualdades, sendo, portanto, uma realidade partilhada por expressividade imagético-performativa. Tendo essa premissa em vista, são os acordos coletivos que determinam a realidade partilhada. Se os acordos são representativos, a realidade partilhada pode configurar, dessa forma, arbitrariedades. Na república platônica, por exemplo, Rancière destaca que 
Teatro e assembleia são duas formas solidárias de uma mesma partilha do sensível, dois espaços de heterogeneidade, que Platão deve repudiar ao mesmo tempo para constituir sua República e a vida orgânica da sociedade. Arte e política estão, assim, ligadas aquém de si mesmas como formas de presença de corpos singulares em um espaço e em um tempo específicos. Platão excluía ao mesmo tempo a democracia e o teatro para projetar uma comunidade ética, uma comunidade sem política. (RANCIÈRE, 2010, p. 22).

Não por acaso, Rancière, crítico às hierarquias de poder e às representações, resgataria as leituras de Schiller sobre a liberdade na vida coletiva, colocando no centro do jogo social a importância da negociação de papéis ao revés da servidão e do trabalho. Ao tratar da figura da deusa Juno e sua expressão imparcial, ele diz:

O que a "livre aparência" da estátua grega manifesta é a característica essencial da divindade, sua "ociosidade" ou "indiferença". O apanágio da divindade é nada querer, estar livre da preocupação de se propor metas e ter que realizá-las. [...] Diante da deusa ociosa, o espectador se encontra em um estado que Schiller define como de "livre jogo". (RANCIÈRE, 2010, p. 23).

Sem indução e aberta a negociações de sentido, a representação deveria dar lugar ao jogo político praticado como exercício de liberdade. É a partir do livre jogar que investigamos a cabo as relações, as motivações, e exercemos uma participação política efetivamente criativa e livre de condicionantes. É a apropriação do livre jogar que garante face e voz aos membros do coletivo, mas é nele que se acentuam as diferenças tão ameaçadoras ao Leviatã.

Tendo em vista Benedict Anderson e a sua reflexão acerca da "nação imaginada", cabe dizer que não se tratava apenas de desenhar um discurso nacional, mas de fazer ebolir esse sentimento como força motivadora. Segundo o autor, depois do advento da imprensa, são fortalecidos os imaginários sobre o mundo. Globalmente veiculados, as imagens e os discursos são realocados em territórios locais, de acordo com a conveniência de época. Nesse sentido, a comunicação de massa, aliada ao repertório linguístico, seria a força motriz da comunidade imaginada. Uma tecnologia de manutenção da soberania que, em vez de definir a relação entre cidadão e Estado, se construiria segundo símbolos, úteis para a realização do projeto político, unindo alteridades pelo discurso homogêneo e incisivo. Anderson vai dizer que

Ela (a nação) é imaginada porque até os membros da mais minúscula das nações jamais conhecerão, encontrarão ou ouvirão falar da maioria dos seus companheiros, embora todos tenham em mente a imagem viva da comunhão entre eles. (ANDERSON, 2008, p. 32). 
Numa outra perspectiva, Negri e Hardt (2005, p. 192) nos chamam a atenção para as contradições de um corpo acima da sociedade como corpo político e que, ao mesmo tempo, se constitui como "res publica" ("coisa pública"). Na leitura de Negri e Hardt, a descrença na solidariedade é a ficção contratual que alia o medo ao sentido de proteção. Uma herança que nos persegue desde a formação dos Estados nacionais, apesar das substantivas mudanças decorrentes da globalização. ${ }^{2}$

Logo, mantém-se a relação de vigilância, abdica-se da liberdade pela suposta proteção de ameaças, sendo a participação política na arena pública representativa e mediada por interesses externos. Assim, o contrato social demarca fronteiras éticas, morais e territoriais artificializando o fim da guerra civil com a limpeza sanitarista. Então, mesmo que os critérios de avaliação pactuados sejam os mais racionais, a estetização do crime sempre deixa brechas ao justificado punitivismo do "outro", do que se difere do coletivo uniforme, do que pretende ser autêntico, do que deseja ultrapassar os limites da regulação e controle.

\section{Fotografia e imaginário coletivo}

Em fins do século XIX e início do século XX, a fotografia contribuiu para a identificação de pessoas subversivas e a manutenção da vigilância. O criminalista francês Alphonse Bertillon, por exemplo, foi um grande pesquisador de retratos falados, elaborando extensos catálogos dos tipos humanos dos criminosos de Paris. Nas páginas de seu inventário, os retratos falados (portraits parlés) de perfis humanos eram acompanhados por legendas escritas manualmente com uma combinação de palavras-chave organizadas por linhas e colunas.

2 Os autores consideram que os Estados nacionais não deixaram de ter poder frente à globalização. De forma geral, os Estados ricos e pobres permanecem como estão. Entretanto, cabe ressaltar que suas funcionalidades estão se modificando dentro de um novo marco de referencial global, produzindo uma globalização das figuras de autoridade e articulações globais de resistência, uma desnacionalização. Eles seguem desempenhando papéis econômicos e políticos para garantir não mais interesses nacionais, mas estruturas de poder globais emergentes (Negri; Hardt, 2005, p. 193). 


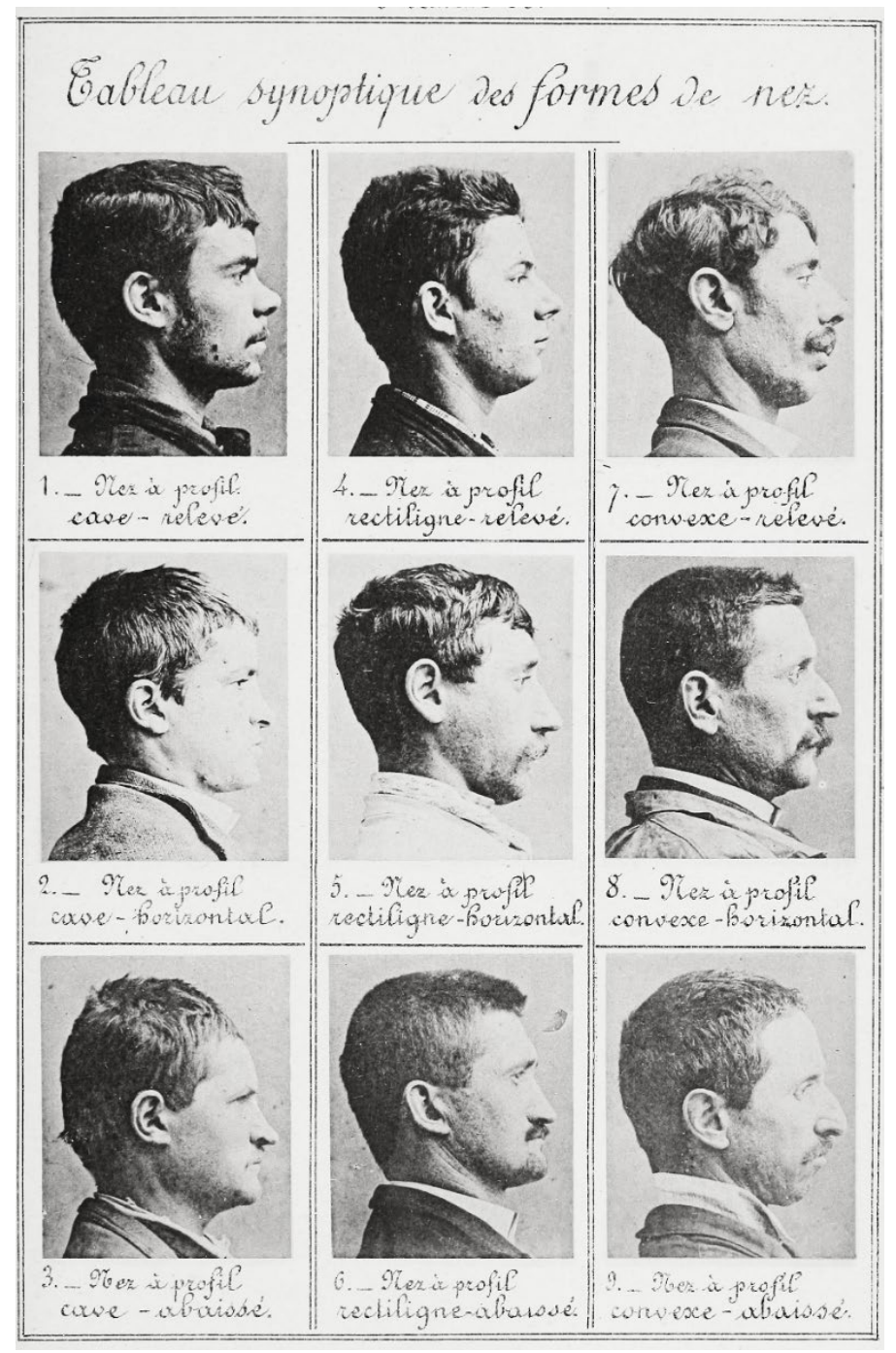

Figura 2 - Alphonse Bertillon, Tabela sinóptica dos formatos de nariz, 1893, ficha criminal redigida, ilustrada com fotografias (fonte: Wikimedia Commons)

A descrição do criminalista buscava ser precisa e identificar a distância entre o nariz e a boca e descrever, com riqueza de detalhes, as características de cada infrator por suas atribuições físicas. Seu inventário colaborou para que a polícia pudesse se valer da estética e identificar infratores, mérito que lhe rendeu uma longa carreira até o fim de sua vida. O retrato judiciário, nesses termos, comunga com os padrões das fotografias científicas a crença no tipo e na utilização de sua imagem como prova da exatidão teorizada. Era preciso uma imagem nítida, realizada em estúdio e com modelos imóveis, a fim de garantir a qualidade da imagem. Annateresa Fabris (2002, p. 32) comenta que a convicção de que existe um corpo criminoso, somada à crença de que existe um corpo doente, valida a identificação das patologias médicas e também das patologias sociais. Segundo a autora, 
A prova pela imagem é um dispositivo que, no século $X X$, lança mão para poder criar um poderoso sistema de defesa numa sociedade que estava se confrontando com um fenômeno inédito: a massa. Paralela à definição do corpo burguês, do corpo que respeitava a lei, e à definição do corpo criminoso, do corpo que coloca em risco a sociedade. Reduzido a um biotipo, esse corpo será passível de arquivamento e classificação, proporcionando uma identificação alicerçada nos desvios da média. Nesse contexto, a fotografia confere um novo significado à definição de identidade. (FABRIS, 2002, p. 33).

Seria o inventário racional de Bertillon uma ferramenta para justificar os abusos de poder? Da ferramenta útil à captura e apreensão de bandidos, o retrato também serviu para categorizar o desviante em potencial, justificando não só a apreensão policial dos supostos infratores frente ao judiciário, mas a eficiência do Estado na manutenção da ordem por vias da violência, dedicando à população as imagens de seus algozes sociais.

As identificações de criminosos nos romances policiais foram pensadas a partir da ideia de traço e é justamente esse elemento a peça-chave para os estudos científicos. Por muito tempo, foi justo o traço que deu à fotografia o status de ferramenta fundamental à documentação e, justo ele, que mais contribuiu para que ela fosse destituída do status de arte. ${ }^{3}$ Baudelaire, por exemplo, foi categórico quando comentou que

A fotografia deve servir às ciências e às artes de forma humilde. [...] que ela salve do esquecimento as ruínas oscilantes e as coisas preciosas cuja forma desaparecerá e que necessitam de um lugar nos arquivos de nossa memória [...]. Mas, se Ihe for permitido invadir o domínio do impalpável e do imaginário, tudo que só é válido porque o homem Ihe acrescenta a alma. (BAUDELAIRE apud DUBOIS, 1993, p. 29).

Na tentativa enfática de evidenciar a fotografia como instrumento de uma memória documental do real, a argumentação de Baudelaire, segundo Philippe Dubois (1993, p. 30), legitima a importância em se conservar o traço do passado ou documentar os traços presentes, imunizando as evidências dos discursos imagináveis, aos quais esses signos se filiavam. Essa separação entre o documental e o artístico, nas palavras de Dubois, não apenas reduz o caráter criativo da fotografia, mas

3 A curiosa disputa entre Louis-Jacques Daguerre e Hippolyte Bayard pela autoria da primeira câmera fotográfica ilustra a relação entre a produção da realidade e a fotografia. Em 1939, enquanto a invenção do daguerreótipo era ovacionada pela academia, as impressões fotográficas inventadas por Bayard foram invisibilizadas. Indignado com essa situação, Bayard produz um autorretrato performando sua própria morte, sendo essa a primeira utilização da fotografia como ferramenta discursiva de produção de realidade e curiosamente o atestado de que um dia ela poderia vir a ser entendida como arte. A história em detalhes é narrada em Batchen (2004, p. 29-31). 
garante à arte "uma redoma elitista e uma antifinalidade, livre de qualquer função social e livre de qualquer arraigamento na realidade" (1990, p. 30).

Por outro lado, a arte indaga a realidade científica elaborando-a como ficção. Nesse trajeto, encontramos com as imagens das expedições Thayer (1865 e 1866), comandadas pelo zoólogo suíço Louis Agassiz e problematizadas na obra Assentamentos (2013), de Rosana Paulino. A intenção da empreitada científica a que fazemos referência implica contrapor negros e brancos para comprovar a superioridade e a necessidade do branqueamento do povo brasileiro. A teoria previa constatar que a miscigenação era problemática, uma vez que a mistura racial provocaria - necessariamente - degeneração. Augusto Stahl é o carioca autor das fotos, responsável por mapear tipos raciais "puros" e registrar a fisionomia desses corpos em três ângulos: de frente, de costas e de perfil. Rosana Paulino se apropria dessas imagens a fim de revisar a história e revelar as profundas raízes do preconceito, afirmado por traços estéticos com forte influência discursiva. 


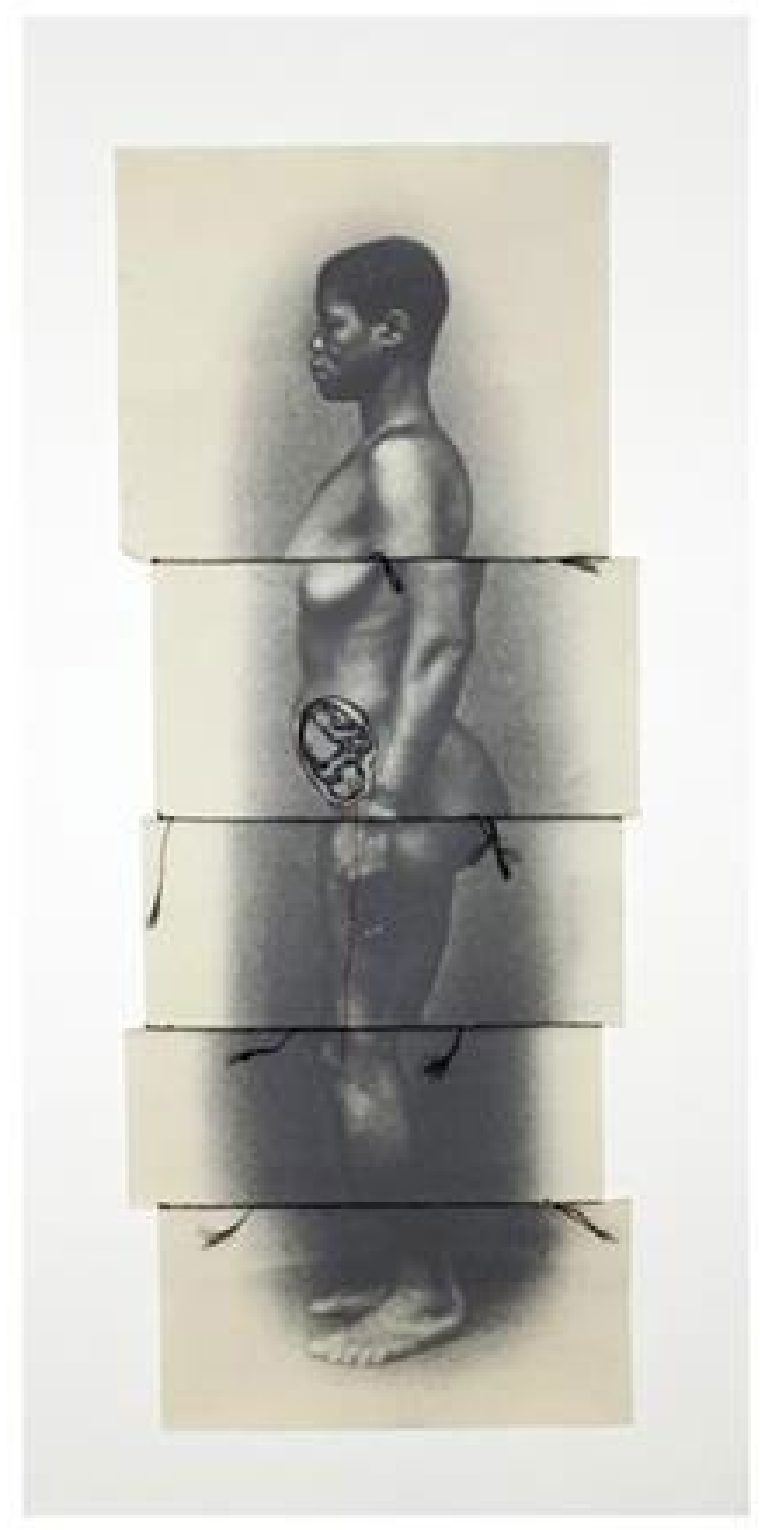

Figura 3 - Rosana Paulino, Assentamentos, 2013, detalhe de instalação no Museu de Arte do Rio durante exposição individual em 2019 (imagem cedida pela artista)

Impressa em tamanho real, a imagem embasa a crítica da artista que propõe, em seu trabalho, uma revisão sobre a figura dos negros brasileiros na história, bem como a relação entre suas imagens e o discurso cientificista. ${ }^{4}$

A apropriação do traço como elemento da linguagem fotográfica não se restringe às pesquisas históricas, mas endereça questões relevantes à memória partilha-

4 O trabalho de Rosana Paulino e a problemática colonialista foram discutidos na comunicação de $S$. C. Geraldo, "O corpo negro e as marcas da violência colonial", no XXXVI Colóquio do Comitê Brasileiro de História da Arte, Campinas, 2016. 
da e àquilo que aprendemos a assimilar como parte dos nossos hábitos físicos e mentais. Segundo Seligmann-Silva (2014, p. 29), são os artistas contemporâneos, empenhados em resgatar arquivos obsoletos, aqueles que mais se apropriam do traço como inscrições políticas, instalando novas reflexões sobre a história frente à amnésia em que mergulhamos atualmente. Para adentrarmos nesse território, é importante pensarmos, portanto, o traço como elemento afetivo que determina e orienta leituras.

Nos retratos realizados, na década de 1920, por August Sander, as imagens de trabalhadores são organizadas em categorias indumentárias e gestuais de caráter sociológico. Os grupos reunidos pelo fotógrafo exibem traços socioprofissionais. Ao contrário do que acontece com os retratos seriais de Alphonse Bertillon, os quais respeitavam uma mesma pose, Sander aposta nas diferenças. São trabalhadores, burgueses, marginais, militares, famílias na diversidade que subsiste em cada grupo. Evidente se faz a necessidade de Sander em recuperar as identidades que resistiram aos efeitos da guerra. $O$ fotógrafo aposta na diversidade alemã iluminando os diferentes segmentos sociais que compunham o corpo coletivo do país

Nas leituras dos retratos de Sander, uma fotografia ganha destaque. $O$ vendedor turco de ratoeiras (1929) é resultado de equações fotográficas tradicionais, as quais orientam nosso olhar a certas particularidades da imagem.

O típico retrato encenado é enquadrado de modo a priorizar o desfoque do olhar em detrimento da nitidez das marcas faciais em torno da boca. As expressões de apatia e descontentamento características são potencializadas por esse recurso fotográfico, evidenciando assim os maus cuidados. Na visão geral da imagem, esse enfoque soa como um erro fotográfico, mas faz sentido se pensarmos no contexto de produção da imagem. Na época, com a intensa migração turca para empreitadas alemãs, bem como a precariedade das condições dos trabalhadores, a imagem dos imigrantes era comparada à de pessoas sujas, pobres e andarilhas, identidade reforçada pelo olhar de Sander.

E é justo nesse entremeio que encontramos as considerações de Jan Berting (2001) sobre o embate entre coletivismo e as alteridades:

O outro não é concebido como estritamente um ser humano, mas como um ser que tem características específicas, porque ele pertence a um grupo que se distingue de "nós". Pouco importa se as diferenças são "reais" ou "imaginárias", porque a observação do outro é regida por representações coletivas ou de estereótipos a partir do momento que a distinção é feita. (BERTING, 2001, p. 41).

No caso de Sander, a distinção não é discursiva, mas imagética. Nesse aspecto, assistimos à representação do outro numa construção de realidade que pendula entre os preconceitos sociais e o olhar particular do autor do retrato.

Segundo Guimarães (2011), as imagens representam uma inteligência tecnológica que muda a maneira com que vemos. Nesse sentido, muitos recursos foram 
usados pela fotografia para tornar o mundo mais pictórico, aliando as realidades imaginadas produzidas pelo equipamento fotográfico com as possíveis leituras de mundo a partir das imagens. Celso destaca fatos criativos exclusivos da fotografia que nos conduzem às especificidades da linguagem fotográfica. Segundo o autor, "O isolamento do objeto, por exemplo, evidencia a eleição de um tema, abstrai dimensões espaciotemporais e desmaterializa a situação fotografada para a materialização da imagem" (Guimarães, 2011, p. 40). É justo esse isolamento que vimos se repetir tanto nas fotografias científicas quanto nas fotografias documentais. Em ambos os casos, o que está em evidência não é a performance dos indivíduos, mas os tipos humanos.

As considerações de Celso nos levam a crer que vale desconfiar dos recursos fotográficos, como construção de linguagem, investigando os códigos de confecção das imagens como ferramentas para elaborar e/ou orientar leituras sobre a realidade.

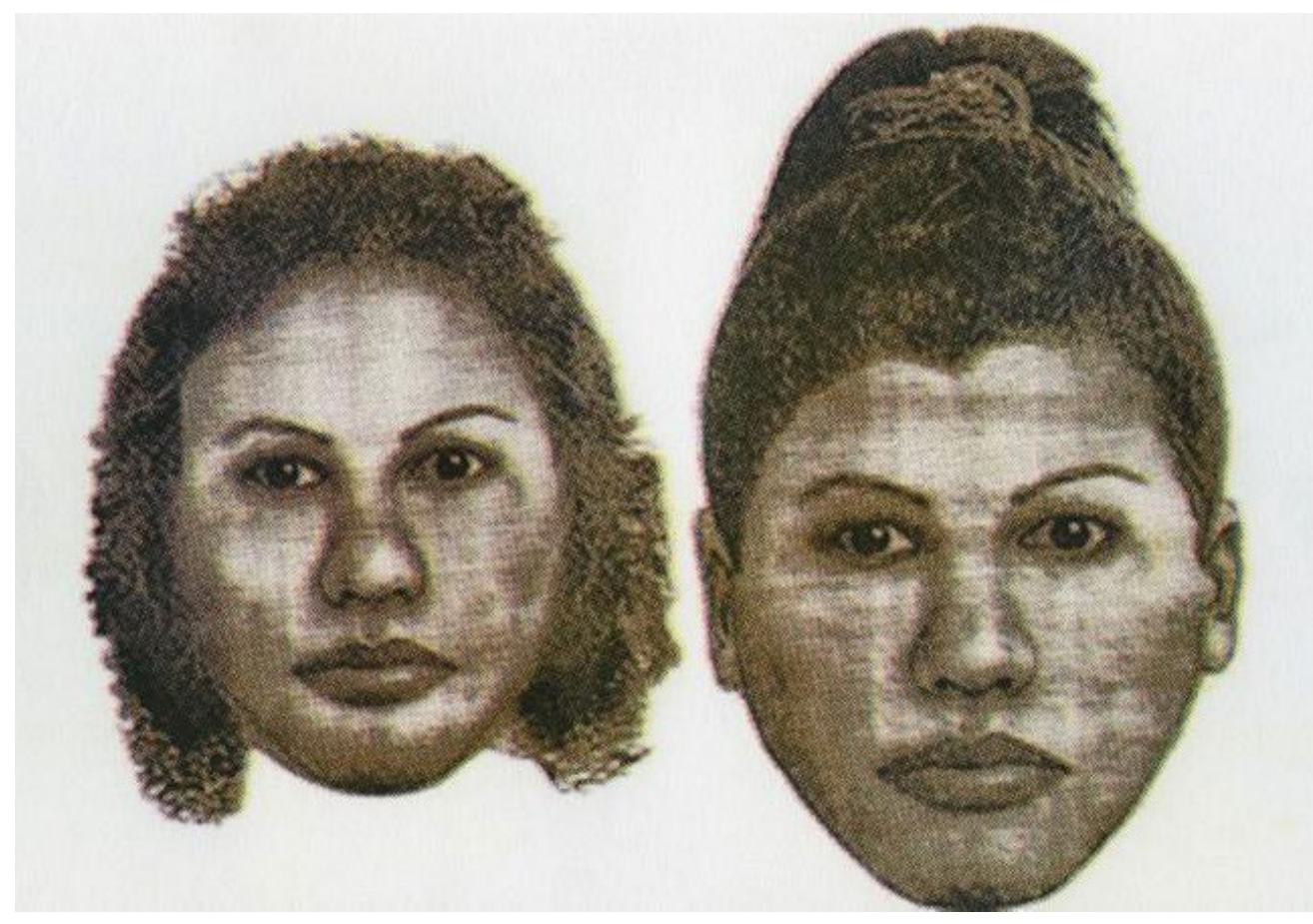

Figura 4 - Coletivo Garapa, Retrato falado - Postais para Charles Lynch, 2015 (imagem cedida pelo Coletivo Garapa)

O trabalho Postais para Charles Lynch (2015) é uma apropriação de imagens de linchamento capturadas da internet, manipuladas digitalmente. Uma transfiguração do lugar da violência ainda latente em nossa memória recente. O fotolivro do coletivo Garapa se subdivide em três partes: uma coleção de imagens manipuladas digitalmente, um roteiro de um linchamento fictício e uma fita magnética que guarda conteúdo desses vídeos. O trabalho questiona o que mostrar e o que esconder quando tratamos de violência contra corpos humanos. Os artistas envolvidos fizeram cópias de telas de vídeos que viralizaram nas redes sociais e na grande mídia. 
A interferência digital junto de comentários coletados do canal no YouTube causa ruídos na imagem. O resultado disso pode ser interpretado como uma metáfora do que acontece na arena pública, sendo o ruído uma consequência do volume de comentários e imagem noticiada diariamente, consequência, portanto, da sedimentação de informações no imaginário coletivo.

A dona de casa Fabiane Maria de Jesus, de 33 anos, morta em Manguinhos IV/ Guarujá por ser confundida com uma suposta satanista sequestradora de crianças, é uma das protagonistas dos vídeos do Garapa. Nesse episódio, o retrato falado da suposta bruxa, veiculado na mídia nacional, foi justo a imagem que levou os vizinhos de Fabiane a persegui-la até a morte, sendo esse retrato desdobramento longínquo das fotografias criminais do século XIX, que auxiliavam a polícia a identificar os criminosos pela fisionomia.

O efeito copycat, ${ }^{5}$ que nada mais é que a relação entre as imagens de intolerância disseminadas pela mídia e o desejo equivocado de justiça, resume a alquimia entre o medo do outro e o consequente punitivismo. O fenômeno de copycat é identificado por Joanna Aragão (2014) como sendo a força motriz para vários dos linchamentos que aconteceram no Brasil em meados de 2015, sendo boa parte deles contra a população negra. Em cartas a Charles Linch, é denunciado não só o número expressivo de linchamentos, mas a comoção social das pessoas em perseguir os tipos humano estereotipados como subversivos. ${ }^{6}$

5 Termo utilizado por Loren Coleman em The copycat effect: how the media and popular culture trigger the mayhem in tomorrow's headlines (2004).

6 Vale lembrar que a palavra "linchamento" veio da história vivida por Charles Lynch, sujeito que durante a Guerra de Secessão se predispôs a perseguir, julgar e violentar aqueles que cometessem "crimes graves". Não por acaso, a prática de violência recaía sobre negros e negras, já perseguidos pelos estados sulistas norte-americanos. Foi em homenagem a Lynch que o Garapa reuniu imagens de linchamentos documentados pela grande mídia brasileira. Assim como acontece nos casos de violência cometidos por Lynch, acontece com as imagens do "intolerado" nos diferentes frames captados pelo Garapa via YouTube. 


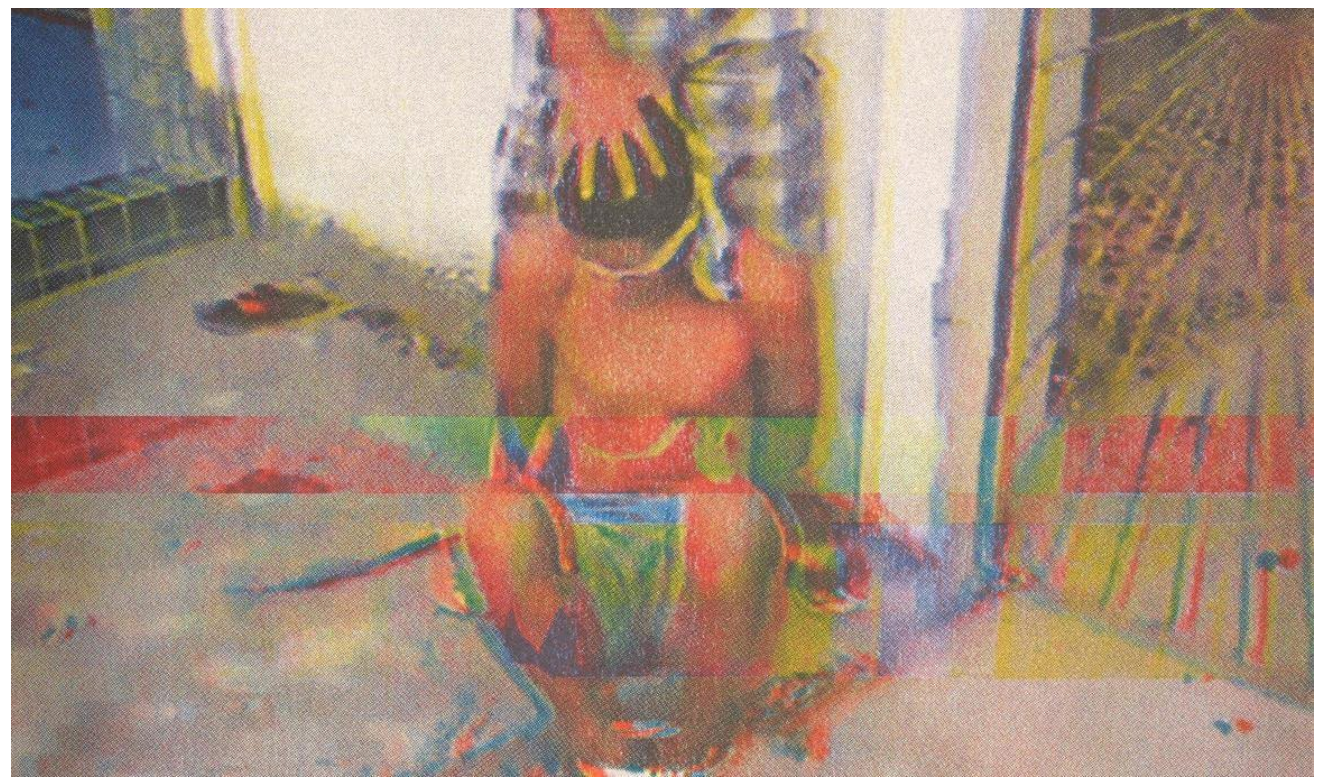

Figura 5 - Coletivo Garapa, Garoto amarrado ao poste - Postais para Charles Lynch, 2015 (imagem cedida pelo Coletivo Garapa)

No corpo coletivo de Hobbes, mediado pelo contrato social, a violência praticada pelo Leviatã se justificaria pela escrita e pela lei. Entretanto, no corpo coletivo contemporâneo, amadurecido pelo capitalismo, a partir da aliança entre empresariado, mídia e Estado, é exigido algo das imagens que justifique os interesses dos novos agentes reguladores, que, na lógica do capital, reduzem a participação cidadã à força de trabalho e ao consumo.

É nesse terreno que se instala a disputa pelo poder representante, que implica reforçar o imaginário sobre o organismo social e as patologias que dele devem ser eliminadas. Acontece que a hierarquia que estabelece poder aos representantes do Estado, sejam eles oficiais ou oficiosos, é a mesma que incide sobre os corpos que merecem morrer.

A mídia, ao que dá a ver a obra do coletivo Garapa, é uma peça fundamental para a disseminação da violência. $O$ vídeo do adolescente amarrado ao poste ganhou destaque após a jornalista Rachel Sheherazade, no Jornal do SBT, defender, em canal aberto, os 15 homens acusados de prender um suposto assaltante com tranca de bicicleta em uma rua do bairro Flamengo, no Rio de Janeiro. Segundo Sheherazade, no vídeo intitulado Adote um Bandido:

Num país que sofre de violência endêmica, a atitude dos vingadores é até compreensível. O Estado é omisso, a polícia desmoralizada, a Justiça é falha [...]. O que resta ao cidadão de bem, que ainda por cima foi desarmado? Se defender, é claro. (RACHEL..., 2014). 
Ferindo a ética jornalística da imparcialidade e incentivando posturas extremadas contra os Direitos Humanos, a opinião da jornalista foi considerada relevante por boa parte dos setores conservadores da sociedade, deixando aos mais sensatos questionamentos sobre o papel do Estado diante do linchamento e da posterior declaração da jornalista. $O$ estereótipo do suposto bandido respeita tendências da segregação não só entre os que produzem e os que são considerados um peso para os que não produzem. Trata-se de uma segregação pela cor de pele, por uma parcela branca da população que se abstém da sua própria história, e uma outra parcela que carrega na pele a herança da escravidão.

Fyodor Pavlov-Andreevich (2016), na performance Cadeado, busca problematizar a associação dos linchamentos com a estética, chamando atenção para o racismo. Ele elabora uma performance durante sete horas, rememorando a cena de humilhação sofrida pelo mesmo jovem negro retratado numa das imagens modificadas em Postais para Charles Lynch. O trabalho é uma parte da série de performances que compõem os Monumentos temporários, trabalho em que Feodor desafia os limites do próprio corpo para abordar a desumanidade e a resistência em situação de tortura. Documentada, a performance deu origem a um vídeo em preto e branco. A experiência vivida pelo artista no Rio de Janeiro, entretanto, se distancia significativamente daquela passada pelo jovem negro. $\mathrm{O}$ artista russo, loiro de pele clara, diz receber a atenção de vários passantes que, preocupados com seu estado, não desconfiam da desumanidade, mas lhe oferecem ajuda.

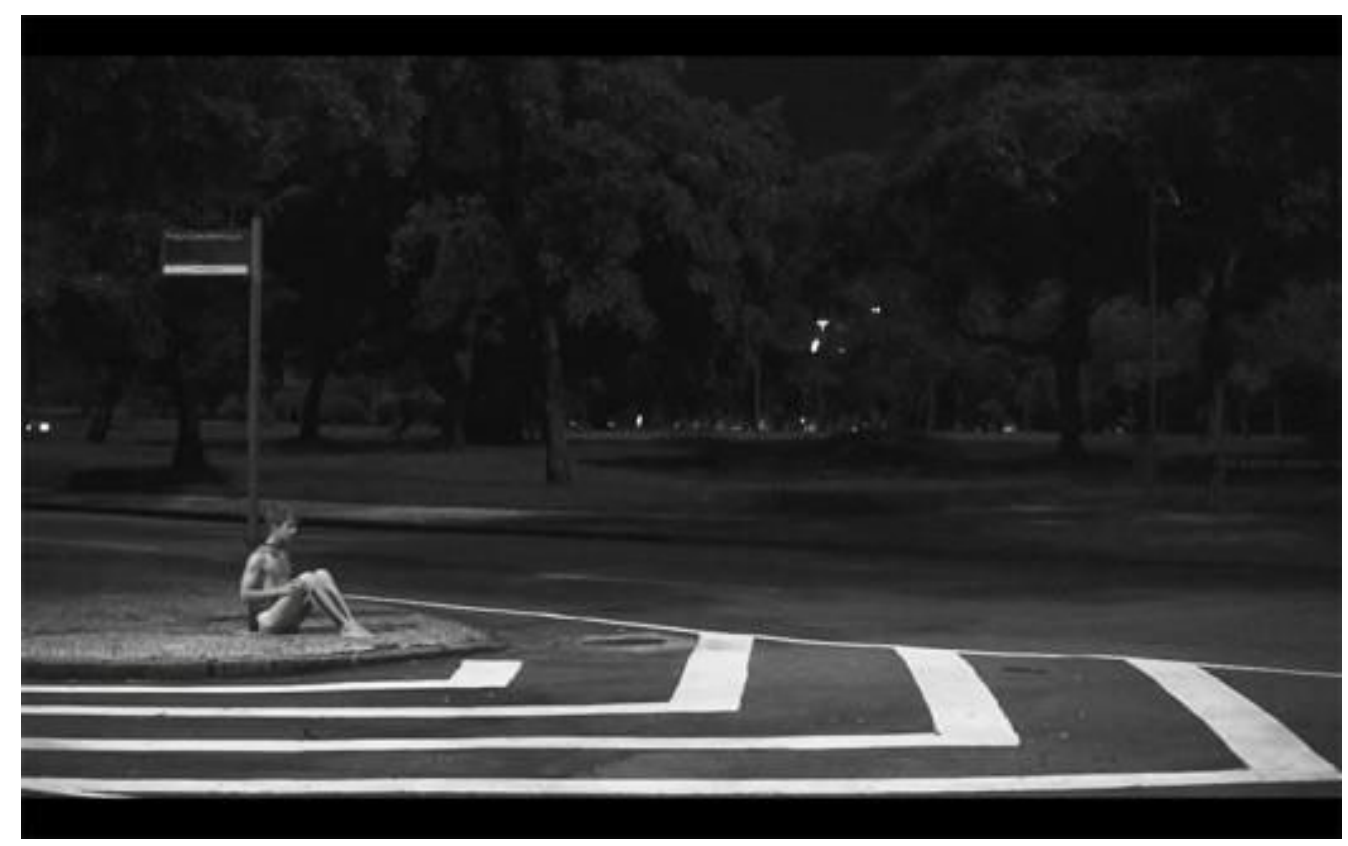

Figura 6 - Fyodor Pavlov-Andreevich, Temporary monument \#6: cadeado, 2016, fotografia de performance (imagem cedida pelo artista) 
A segregação pelas diferenças estéticas marca o corpo coletivo, as práticas do Estado e as ficções reguladoras desse mesmo Estado, sendo a imagem o álibi para a violência aplicada e reproduzida.

O que é um crime, quando o próprio modo de funcionamento da justiça se faz inseparável de um projeto de atualização perpétua da injustiça como fantasia de controle? [...] mesmo quando as máquinas de desperceber conflitos e desigualdades estruturantes projetam - sempre arbitrariamente - verdades cuja promessa é de serem neutras, que significa ser um criminoso? O que é segurança? [...] quais os corpos merecem ser matáveis? (MOMBAÇA, 2016, p. 3-4).

Jota Mombaça fala sobre a ficção da violência numa abordagem lúcida acerca do corpo que não se enquadra no coletivo civilizado ou nos padrões civilizatórios. Em suas perguntas, estão respostas ocultas sobre um modus operandi de ordenação e moralismo que inclui a morte e a violência. O punitivismo fundamental à força do Leviatã, como abstração coletiva, é parte de uma máquina regulatória, a qual intensifica segregações por vias de imagens e imaginários que alimenta.

Nos corpos coletivos ocidentalizados, a guerra civil a ser evitada é sempre uma notícia iminente. Os parâmetros de crime e segurança, nesses termos, estão num jogo de espectros, em que cada medo e insegurança gera uma justificativa sanitarista.

Jota (2016) problematiza o monopólio da violência como uma ficção. Ela diz que vivemos perante um acúmulo de imagens ficcionais disseminadas entre os meios de comunicação e utilizadas nos julgamentos jurídicos e abordagens policiais. $\mathrm{Na}$ sua visão, a neutralidade da justiça é uma promessa falida, pois continua a segregar direitos, liberdades, privilégios e interditos. Nesse sentido, as imagens reproduzidas nos noticiários e o discurso racionalizante da justiça e até mesmo as narrativas de seriados e filmes são vias para a disseminação das imagens dos corpos que devem morrer.

Grada Kilomba (2010, p. 172) contribui para a questão ao problematizar os silenciamentos que o racismo provoca, colocando no centro da discussão a falta de reconhecimento do branco no processo de colonização e a naturalização do punitivismo do outro. A autora diz:

Embora a plantação e seus frutos de fato pertençam "moralmente" à(ao) colonizada(o), o colonizador interpreta este fato perversamente, invertendo uma narrativa que lê tal fato como roubo. "Estamos levando o que é Deles(as)" torna-se "Eles/elas estão tomando o que é Nosso". Estamos lidando aqui com um processo de recusa, no qual o mestre nega seu projeto de colonização e o impõe sobre o(a) colonizado(a). É este momento - no qual o sujeito afirma algo sobre o outro que se recusa a reconhecer em si próprio - que caracteriza o mecanismo de defesa do ego. (KILOMBA, 2010, p. 172). 
Mais uma vez o medo do outro assola a vida coletiva. Entretanto, é colocada sobre a sociedade ocidentalizada uma necessidade de autoanálise em que se possa reconhecer a violência que a habita ao mesmo tempo que se traveste de proteção. A relação entre o que se apresenta na realidade e a imagem invertida é nada mais do que aquilo que o colonizador teme reconhecer, do que os sujeitos desse espaço coletivo eurocêntrico, de raízes teóricas hobbesianas, temem reconhecer. Kilomba vai dizer que, nessa relação, o sujeito negro, em toda a sua autenticidade, é reduzido a uma imagem a ser expurgada, ao ladrão, ao marginal e às demais figuras que fazem parte de um dado projeto civilizatório não como protagonistas, mas como antagonistas.

A experiência de pessoas marginalizadas pela colonização e a necessidade de sanitarismo se tornam então uma experiência corporal "traumática". Diferença, estranhamento, incompatibilidade e falta de afinidade são, por fim, os julgamentos estético-corporais que ofuscam a imagem espelhada que o colonizador se nega a reconhecer como ego.

\section{3 - Sobreviver, forçar enquadramentos}

Em Rua de mão única (1987, p. 244), Benjamin recomenda que olhemos as imagens do passado, ou as imagens de arquivo, não reconhecendo o que elas de fato foram, mas que encontremos seus silêncios. Afinal, abrir o arquivo significa "acordar as imagens" para um outro tempo, descobrir como elas se revelam como memória e desejo. Nessa perspectiva, a gama de retratos familiares, acumulados ao longo do tempo e muitas vezes afastados do seu lugar de origem, tem muito a nos dizer. Há de se considerar as variações inevitáveis das fotos espontâneas. Mas, em ocasiões solenes, a pose e o figurino são exigências sociais que marcam presença.

Ôrí foi um filme gravado entre as décadas de 1970 e 1980 e retrata o movimento negro no Brasil da época. Em um trecho do filme, imagens dos "bailes black" paulistanos são exibidas. Em cena, os desfiles de homens e mulheres com "cabelo black power" e "tranças nagô", passos de funk e manifestações de empoderamento a partir da afirmação estética claramente inspiradas pela cultura negra norte-americana. Em contraposição a essas imagens, o filme exibe a repressão e perseguição policial aos negros, sobretudo aqueles que exerciam algum protagonismo nos movimentos sociais e culturais organizados. Em um trecho da narração que acompanha o filme, a historiadora e ativista Beatriz do Nascimento ${ }^{7}$ (Ôrí, 1989, 30min35s-30min50s) vai dizer: "A invisibilidade está na raiz da perda de identidade". Ela nos chama atenção para a necessidade em se afirmar a estética negra cotidianamente silenciada pe-

7 Vale lembrar que Beatriz, mulher negra, foi vítima de um homem que tentou "fazer justiça" com as próprias mãos. Ao não tolerar a interferência de Beatriz em uma discussão com sua esposa, amiga de Beatriz, o homem ameaça a historiadora de morte publicamente e decide assassiná-la posteriormente. O episódio de violência é mais um capítulo da longa história de intolerâncias e ódio contra os corpos matáveis de que fala Mombaça (2010). 
los padrões de branqueamento e colonização. A desvalorização da cultura estética negra e a incisiva afirmação do branqueamento impulsionaram o enquadramento estético da população negra aos padrões de branqueamento travestidos de projeto civilizatório. Segundo Beatriz, esse rebaixamento contribuiu para perseguições aos que esteticamente são rotulados como marginais. E é justo por esse motivo que a performance estética está no epicentro da questão como uma forma de empoderamento político.

Nas cenas subsequentes de Ôrí, Beatriz faz uma análise crítica de algumas de suas fotografias (Ôrí, 1989, $31 \mathrm{~min} 53 \mathrm{~s}-32 \mathrm{~min} 12 \mathrm{~s}$ ). Na primeira imagem, a fotografia de sua carteira de identidade, Beatriz diz não se reconhecer. Suas roupas e postura não dizem sobre o que ela é, mas o que ela deveria ser. Sua análise continua, dessa vez, em relação a um retrato realizado em alguma ocasião de formatura. Sobre a imagem, Beatriz diz: "Essa outra foto me remete aos meus mitos vividos no cinema. Uma atriz de cinema, Marilyn Monroe, ou minha irmã Carmen, que já era normalista formada no Rio de Janeiro. Com essa bata branca em crepe importada, essa tola feita pela família [...]". Na terceira leitura de imagem, ela resgata uma fotografia de uma cerimônia católica de primeira comunhão tirada quando ela tinha nove anos de idade. Sobre a imagem, ela diz: "Toda minha vida foi me separar dessa concepção. Esse foi um momento de grande depressão, um momento de fuga. Ao mesmo tempo, um encontro com Cristo na primeira comunhão. Podemos dizer que a falsa conivência é, nesse sentido, um mecanismo de defesa para que o outro não julgue sua imagem como uma verdade desagradável". Como bem lembra Kilomba (2010, p. 180), a quebra com o racismo não está apenas numa abertura de espaço aos socialmente marginalizados ou no reconhecimento das falhas da sociedade atual, mas numa revisão de sua estrutura incorporada, imagética, vocabular, habitual, ou seja, numa real revisão dos privilégios, dos julgamentos estéticos que tecem o imaginário.

O artista holandês Roy Villevoye, no trabalho Presents (1990), realiza, mediante intercâmbios e trocas simbólicas entre culturas, uma reflexão sobre a relação da colonização através de roupas deslocadas de uma cultura para outra. Nesse projeto, o artista presenteia três homens da cultura Asmati com três roupas "ocidentais". Num segundo momento, quando o artista fotografa os homens, percebe que eles parecem interpretar as roupas. Cotton (2010, p. 35) vai dizer que a imagem fotográfica que sintetiza essa relação "reflete os históricos elos de comercialização entre ambas as culturas e o zelo implícito dos ocidentais em impor suas preferências e senso de decoro aos nativos colonizados". Acontece que essa imposição colonial implica necessariamente o abandono e a extinção dos padrões culturais nativos.

De fato, a imagem segue a composição das fotografias realizadas durante as expedições antropológicas do século XIX, em que o senso de decoro do colonizador sobre o colonizado era violentamente explícito. Reproduzindo, sobretudo, variáveis estéticas semelhantes àquelas usadas pelos fotógrafos europeus em viagens colonialistas, a fotografia de Roy Villevoye comenta acerca de certo repertório de ima- 
gens que ilustraram a história da cultura ocidental e que se acumulam em nossa memória afetiva.

O enfileiramento dos homens e a repetição da mesma pose expressam ao leitor um dado discurso realocado na ironia do artista. Bataille (1929) traz contribuições pertinentes para pensarmos a qualidade desse discurso imagético ao nos apresentar a "forma derrisória" da pose fotográfica, discutida no conhecido artigo "Figura humana". Ao analisar a fotografia de um casamento em Seine-et-Marne, ele comenta que "se trata dessa imagem de convivas empoeirados, personagens petrificados, fixados na goma de seus colarinhos apertados demais, tanto quanto a própria pose fotográfica" (p. 201).

A "forma derrisória" de Bataille, resgatada por Didi-Huberman (2015), se materializa em cenas que reúnem pessoas intencionalmente "coladas e enfileiradas em seu ritual como borboletas numa placa naturalista". Ao comparar os artigos da Documents $n^{\circ} 4$, em que foi publicado o artigo de Bataille, Didi-Huberman (2015, p. 58-60) comenta sobre a reprodução da "forma derrisória" em outras composições fotográficas que o corpo burguês, com as vestes do colonizador, contrasta com o corpo nu ou seminu do colonizado. Em sua análise, é interessante notar o quanto a pose está enraizada na linguagem fotográfica burguesa e o quanto a interpretação cultural da fotografia condiciona os corpos fotografados, como se nesses corpos em pose se fixassem a marca de uma cultura, as camadas de gestos e vestimentas interpretadas, de maneira a modelar à realidade, conforme o discurso que se pretende comunicar.

Nesse ínterim, são os retratos burgueses com suas variáveis estéticas e periféricas da pose e interpretação corporal dos fotografados que se tornam as grandes expressões da "forma derrisória". A exemplo disso, numa atualização reformulada, a fotografia de Roy ecoa imagens do nosso repertório histórico, desde o tradicional retrato burguês até as expedições colonialistas, comungando numa mesma superfície fotográfica as performances de distinção social pela vestimenta. Podemos dizer que o artista agrega em uma só imagem a circularidade dos discursos sobre a pose, fazendo convergir na superfície fotográfica as memórias institucionalizadas pela história. O ponto comum entre essas memórias é o consumidor colonizado, que se materializa não apenas na avaliação crítica da herança colonialista do fotógrafo e de seus possíveis leitores, mas na artificialização da experiência que a imagem evoca.

Nos registros de Chichico sobre a Diamantina dos anos 1920, encontramos uma curiosa cena. O fotógrafo cronista, dono do único estúdio de revelação existente no Vale do Jequitinhonha na época, exibe uma cena urbana, situada entre a referência do progresso e o exotismo cultural. Em evidência, estão o congelamento da pose e a encenação das roupas. Manequins, adultos e crianças compartilham o enquadramento do fotógrafo e performam, para o autor, um certo status social. Como uma espécie de vitrine, os personagens compartilham a figura pública ou publicizada das etiquetas da moda, atestando um tipo de colonização que se dá pela via do 
consumo. Apenas duas crianças parecem desviar da proposta sugerida, o que evidencia o aspecto cotidiano da cena. Esse ato de rebeldia soa como uma metáfora esperançosa para a construção social que se apresenta.

Nas palavras do teórico Giorgio Agamben (2007, p. 29), "o sujeito fotografado exige algo de nós", provocando nossa leitura interpretativa sobre o que significa sua existência:

Mesmo que a pessoa fotografada fosse hoje completamente esquecida, mesmo que seu nome fosse apagado para sempre da memória dos homens, mesmo assim, apesar disso - ou melhor, precisamente por isso -, aquela pessoa, aquele rosto exigem seu nome, exigem que não sejam esquecidos. (AGAMBEN, 2007, p. 29).

Os corpos não colonizados pela tradição europeia ou avessos aos enquadramentos culturais que a tradição propõe, quando vestidos de cidadania burguesa, deixam para segundo plano os preconceitos que enfrentam, a desigualdade social e a conotação marginal no sentido mais amplo do termo.

Willian A. Ewing (1994, p. 324) propõe a categoria do político para toda a fotografia que tem como objeto o ser humano. Ele comenta que todas as fotografias do corpo são potencialmente políticas, na medida em que podem ser usadas para controlar opiniões ou influenciar ações. Assim, é impossível pensar apenas nos sujeitos fotografados, precisamos revisitar as condições e intenções possíveis para que esse sujeito exista como imagem.

\section{4 - A imagem do cidadão}

Após a consolidação das leis trabalhistas em 1943, Assis Horta recebeu em seu estúdio em Diamantina um grande número de trabalhadores que tinham por necessidade uma fotografia $3 \times 4$ a para a carteira de trabalho. A pose destinada a esse documento respeitava os mesmos padrões franceses das fotografias judiciárias, inspiradas nas normas de identificação de Alphonse Bertillon, como visto anteriormente. Instituído por Getúlio Vargas, o artigo $13^{\circ}$ da Constituição Federal Brasileira frisava que a Carteira de Trabalho e Previdência Social seria, a partir de então, obrigatória para o exercício de qualquer emprego, inclusive de natureza rural, ainda que em caráter temporário. Para sua emissão, era necessário, segundo o Art. 16, ter, além do número de série e data de emissão, uma fotografia do trabalhador com menção do dia em que a foto teria sido tirada. Muitos estúdios fotográficos se valeram da necessidade do $3 \times 4$ para oferecer serviço especializado à comunidade. Novamente a pose, novamente a imagem institucional. A fotografia, que, até então, era solicitada para solenidades e registros de atividades burguesas, se democratizou, visto a exigência legal então instituída. 
Trabalhadoras e trabalhadores que passaram pelo estúdio de Assis Horta tiveram seus primeiros registros fotográficos feitos pela necessidade da carteira de trabalho. A pessoa retratada nessa imagem deveria se enquadrar em certos protocolos, como não expressar emoções e se vestir com roupas "apresentáveis". Horta, zeloso pela qualidade dos seus retratos e pela boa apresentação dos fotografados, muitas vezes emprestava roupas e assessórios para seus clientes, sobretudo para as pessoas mais humildes, que não tinham condições de comprá-las. Padrões estéticos inocentemente afirmados na gentileza do fotógrafo, mas carregados de traços segregadores. Entretanto, existe um aspecto ainda mais significativo quando retomamos essas imagens. Trata-se da expressividade do documento no corpo coletivo e na sua relação com o Estado.

José Murilo de Carvalho (2002) nos chama a atenção para a categorização do trabalhador-cidadão, a partir da emissão da CTPS (Carteira de Trabalho e Previdência Social). Fruto do Estado Novo, a Consolidação das Leis Trabalhistas (CLT) foi o ponto nevrálgico para a associação entre trabalho e cidadania. O sujeito empregado era tido como parte do corpo coletivo, assegurando a dinâmica econômica do país e a manutenção da vida familiar. A figura do trabalhador, nesse cenário, era equivalente à figura do cidadão. Entretanto, como analisa Carvalho (2002, p. 104), a CLT foi introduzida num ambiente de baixa ou nula participação política e de precária vigência dos direitos civis, o que nos leva a crer ser duvidosa a leitura dos avanços trabalhistas como conquista democrática, pois pouco contribuíram para o desenvolvimento de uma cidadania ativa. A proposta getulista, que herdara do positivismo comtiano a incorporação do proletariado à sociedade pela seguridade das condições trabalhistas, não necessariamente afirmava a cooperação entre empregados e empregadores. A exemplo do que acontece com o Leviatã, os representantes e os representados deveriam agir em prol do bom funcionamento da sociedade, interesses esses superiores aos individuais ou setoriais. Nessa dinâmica, mesmo que aparentemente todo empregado automaticamente fosse reconhecido como cidadão, o respeito à pirâmide hierárquica de trabalho deveria ser zelado. Segundo José Murilo de Carvalho, os positivistas ortodoxos brasileiros seguiram ao pé da letra essa orientação piramidal à la Leviatã, encarando a hierarquia trabalhista como uma "questão social". A partir de então, se tornou protocolar ter um documento de trabalho para ser enxergado como cidadão, bem como ostentar a imagem burguesa em seus documentos oficiais. Uma tentativa clara de artificialização da vida e de apagamento das desigualdades sociais, expressas pelas condições materiais dos trabalhadores menos favorecidos. A ação do fotógrafo Assis Horta nessa conjuntura não é, em última instância, um ato de solidariedade. É uma alternativa para aquelas pessoas que precisam artificializar a própria existência para se aproximarem da imagem do cidadão. Durante o getulismo, não era preciso ser político ou participar da política, era preciso parecer cidadão. Ainda hoje são os documentos oficiais, como a carteira de trabalho, que livram muitas pessoas das violentas abordagens policiais e do julgamento da sociedade estruturalmente racista. 
É importante notar que o problema da representação não está apenas na discussão sociológica sobre o formato das organizações ou mesmo na crítica de suas contradições internas, mas na própria representação do corpo coletivo. A imagem e a construção de ficções por via de sua expressividade ampliam a reflexão do universo discursivo para o universo imagético. Nesse panorama, a fotografia desempenha um papel importantíssimo como instrumento que atesta e também denuncia a estereotipização. Os registros fotográficos oficiais, como as carteiras de identidade, os retratos familiares com referências na vida burguesa, ou até mesmo os contemporâneos estereótipos midiáticos, são parte desse Leviatã reformulado, que continua a exigir uma vigilância estética, ficcionalizando uma guerra entre "perfis" aceitáveis e aqueles que merecem ser aniquilados.

A exemplo do cruel Estado-Leviatã de Hobbes, os atuais Estados nacionais continuam a pensar o outro em um jogo de espelhos, projetando na imagem que criaram do outro toda a violência que os constitui. Marielle Franco, vereadora carioca brutalmente assassinada em março de 2018, representava diferentes lutas historicamente perseguidas. Mulher, negra, defensora dos direitos humanos, favelada e lésbica, ela foi e é a esperança de que, mesmo com todo o preconceito e sanitarismo, ainda há lugar para a pluralidade na política brasileira. Infelizmente, sua imagem e a sua voz chegaram a camadas da sociedade ameaçadas por suas denúncias, sobretudo quando evidenciava o genocídio negro, arbitrário e pautado pela estereotipização. Entretanto, como bem lembra Diana Taylor, é justamente em tempos de totalitarismo e violência que o corpo se torna o terreno de resistência. A repercussão da morte de Marielle foi um fenômeno incontestável, a reprodução de sua imagem como ato de resistência negra é nossa sugestão para futuras investigações. Esperamos, nesse sentido, que a arqueologia das expressividades silenciadas pelas políticas de repressão e controle possam iluminar as raízes da violência sistêmica nas instituições repressoras e na lógica do punitivismo. Que a imagem esteja a favor, e não contra a política. Marielle Vive!

\section{Referências}

AGAMBEN, G. A comunidade que vem. Lisboa: Presença, 1993.

AGAMBeN, G. O uso dos corpos: Homo Sacer, IV, 2. Boitempo: São Paulo, 2017.

AGAMBEN, G. Por uma ontologia política do gesto. In: Giardino di studi filosofici. Macerata: Quodlibet, 2018. Trad. Vinícius N. Honesko. Disponível em: http:// flanagens.blogspot.com.br/2018/03/para-uma-ontologia-e-uma-politica-do.html. Acesso em: 15 mar. 2018.

AGAMBEN, G. Profanações. (Trad. Selvino J. Assmann). São Paulo: Boitempo, 2007ALMENA, M. C. C. Ficción y fotografia en el siglo XIX: tres usos de la ficción 
en la fotografía decimonónica. In: CONGRESO INTERNACIONAL DE HISTORIA DE LA FOTOGRAFÍA, 4., 2009, Zarautz. Anales [...]. Zarautz: Photomuseum, 2009. Disponível em: https://eprints.ucm.es/14469/1/Ficción_y_fotografía_en_el_siglo_ XIX.pdf. Acesso em: 20 jan. 2018.

ANDERSON, B. R. Comunidades imaginadas: reflexões sobre a origem e a difusão do nacionalismo. São Paulo: Companhia das Letras, 2008.

BARTHES, R. A câmara clara. Rio de Janeiro: Nova Fronteira, 1984.

BARTHES, R. Mitologias. Trad. Rita Buongermino e Pedro Souza. 11. ed. Rio de Janeiro: Bertrand Brasil, 2001.

BATAILLE, G. Figure humaine. Documents, n. 4, p. 201, 1929.

BATCHEN, G. Arder en deseos: la concepción de la fotografia. Barcelona: Fotográfica, 2004.

BENJAMIN, W. Rua de mão única. In: Obras escolhidas. São Paulo: Brasiliense, 1987. v. 2.

BERTILLON, Alphonse. Tabela sinóptica dos formatos de nariz. 1893. Ficha criminal redigida, ilustrada com fotografias. Disponível em: https://commons.wikimedia.org/ wiki/File:Bertillon_-_Identification_anthropométrique_(1893)_285_n\%26b.png.

BERTING, J. Identités collectives et images de l'autre: les pièges de la pensée collectiviste. Hermès, Paris, n. 30, p. 41-58, 2001. Disponível em: http://documents. irevues.inist.fr/handle/2042/14516. Acesso em: 30 out. 2009.

BíBLIA. A.T. e N.T. Português. Bíblia sagrada. Trad. João Ferreira Almeida. Rio de Janeiro: King Cross, 2008.

BOSSE, Abraham. Leviatã. 1651. 1 gravura. Disponível em: https://commons. wikimedia.org/wiki/File:Leviathan_by_Thomas_Hobbes.jpg.

CARVALHO, J. M. Cidadania no Brasil: o longo caminho. 3. ed. Rio de Janeiro: Civilização Brasileira, 2002.

COLETIVO GARAPA. Disponível em: https://garapa.org/.

COLETIVO GARAPA. Retrato falado: postais para Charles Lynch. 2015. 
COLETIVO GARAPA. Garoto amarrado ao poste: postais para Charles Lynch. 2015.

COTTON, C. A fotografia como arte contemporânea. Trad. Maria Silva Mourão Netto e Marcela Brandão Cipola. 2. ed. São Paulo: WMF Martins Fontes, 2013.

DEBORD, G. A sociedade do espetáculo. São Paulo: Coletivo Periferia, 2003.

DIDI-HUBERMAN, G. A imagem sobrevivente: história da arte e tempo dos fantasmas segundo Aby Wargurg. Rio de Janeiro: Contraponto, 2013.

DIDI-HUBERMAN, G. A semelhança informe: ou o gaio prazer visual segundo Georges Bataille. Trad. Caio Meira e Fernando Schieb. Rio de Janeiro: Contraponto, 2015.

DIDI-HUBERMAN, G. O que vemos, o que nos olha. Trad. Paulo Neves. São Paulo: Editora 34, 1998.

DUBOIS, P. O ato fotográfico. Campinas: Papirus, 1993.

EWING, W. A. The body: photoworks of the human body. London: Thames \& Hudson, 1994.

FABRIS, A. Atestados de presença: a fotografia como instrumento científico. Locus, v. 8, n. 1. p. 29-40, 2002.

FANON, F. Os condenados da terra. Juiz de Fora: Ed. UFJF, 2005 [1961].

FLUSSER, V. Filosofia da caixa preta: ensaios para uma futura filosofia da fotografia. Rio de Janeiro: Relume Dumará, 2002.

GERALDO, S. C. O corpo negro e as marcas da violência colonial. In: COLÓQUIO DO COMITÊ BRASILEIRO DE HISTÓRIA DA ARTE, 36., Campinas. Anais [...]. Campinas, 2016.

GUIMARÃES. C. Fotografia subjetiva, abertura ao contemporâneo. Arte \& ensaios, n. 22, p. 34-41, 2011.

HARDT, M.; NEGRI, A. Multidão. Rio de Janeiro: Record, 2005.

HOBBES, T. Leviatã: matéria, forma e poder de um estado eclesiástico e civil. Os Pensadores. 3. ed. Trad. João Paulo Monteiro e Maria Beatriz Nizza da Silva. São Paulo: Abril Cultural, 1983. 
HOFBAUER, A. Branqueamento e democracia racial: sobre as entranhas do racismo no Brasil. Marília: Unesp, 2011. Disponível em: https://andreashofbauer.files.wordpress. com/2011/08/branqueamento-e-democracia- racial_finalc3adssima_2011.pdf. Acesso em: 20 set. 2016.

IMS - INSTITUTO MOREIRA SALLES. Disponível em: https://ims.com.br/.

KILOMBA, G. The mask. In: Plantation memories: episodes of everyday racism. 2. ed. Münster: Unrast Verlag, Auflage, 2010.

LEWKOWICZ, Hoanna Isabely Gomes. A onda de linchamentos no Brasil, o fenômeno copycat e o esvaziamento das normas. Jus, maio 2014. Disponível em: http://jus. com.br/artigos/28268/a-onda-de-linchamentos-no-brasil-o-fenomeno-copycat-eo-esvaziamento-das-normas. Acesso em: 13 maio 2016.

MOMBAÇA, J. Rumo a uma redistribuição desobediente de gênero e anticolonial da violência. Cadernos do grupo de pesquisa Oficina de Imaginação Política. Publicação comissionada pela 32a Bienal de São Paulo. São Paulo: Incerteza Viva, 2016.

ÔRÍ. Direção: Raquel Gerber. São Paulo: [s. n.], 1989. (93 min). Disponível em: https:// www.youtube.com/watch?v=Eh0A5GRiN64. Acesso em: 10 abr. 2016.

PAULINO, Rosana. Disponível em: http://www.rosanapaulino.com.br.

PAULINO, Rosana. Assentamentos. 2013.

PAVLOV-ANDREEVICH, Fyodor. Temporary monument \#6: cadeado. 2016. 1 fotografia de performance.

"POSTAIS para Charles Lynch", Coletivo Garapa | Corpo a corpo. São Paulo: IMS, 2017. 1 vídeo (3 min). Publicado pelo canal imoreirasalles. Disponível em: https://www. youtube.com/watch?v=oy-Ju9RUnpl. Acesso em: 18 out. 2017.

RACHEL Sheherazade - "Adote um Bandido" - SBT BRASIL 04/02/2014. São Paulo: SBT, 2014. 1 vídeo (1 min). Publicado pelo canal Rolou na Net. Disponível em: https:// www.youtube.com/watch?v=gi_O9ko-OWE. Acesso em: 19 out. 2015.

RANCIÈRE, J. A partilha do sensível: estética e política. São Paulo: EXO/34, 2010.

ROSSI, J. P. August Sander e homens do século XX: a realidade construída. 2009. Dissertação (Mestrado em Sociologia) - Universidade de São Paulo, São Paulo, 2009. Disponível em: https://dobrasvisuais.files.wordpress.com/2010/03/august-sandere-homens-do-sc3a9culo-xx.pdf. Acesso em: 15 dez. 2016. 
ROUILLÉ, A. A fotografia: entre o documento e a arte contemporânea. São Paulo: Senac, 2005.

SELIGMANN-SILVA, M. Fotografia como arte do trauma e imagem-ação: jogo de espectros na fotografia de desaparecidos das ditaduras na América Latina. Temas em Psicologia, v. 17, p. 311-328, 2009. Dossiê "Psicologia, violência e o debate entre saberes". Disponível em: http://pepsic.bvsalud.org/pdf/tp/v17n2/v17n2a04.pdf. Acesso em: 3 jun. 2015.

SMITH, A. A riqueza das nações. Rio de Janeiro: Abril Cultural, 1982.

TAYLOR, D. $O$ arquivo e o repertório: performance e memória cultural nas Américas. Belo Horizonte: Ed. UFMG, 2011.

TAYLOR, D.; FUERTES, M. A. (org.). Estudios avanzados de performance. Trad. Ricardo Rubio, Alcira Bixio, Maria Antonieta Cancino, Silvia Peláez. México: FCE; Instituto Hemisférico de Performance y Política; Tisch School of the Arts; New York University, 2011.

A presente pesquisa foi realizada com apoio da Coordenação de Aperfeiçoamento de Pessoal de Nível Superior (Capes), Brasil. 